\title{
Estimation of radiated energy using the KiK-net downhole records-old method for modern data
}

\author{
Hiroo Kanamori, ${ }^{1}$ Zachary E. Ross ${ }^{\oplus 1}$ and Luis Rivera ${ }^{\oplus 2}$ \\ ${ }^{1}$ Seismological Laboratory, California Institute of Technology, Pasadena, CA 91125, USA. E-mail: hiroo@gps.caltech.edu \\ ${ }^{2}$ Institut de Physique du Globe de Strasbourg; UMR7516, University of Strasbourg-CNRS, Strasbourg, France
}

Accepted 2020 January 13. Received 2020 January 6; in original form 2019 August 26

\begin{abstract}
SUMMAR Y
We use KiK-net (NIED) downhole records to estimate the radiated energy, $E_{\mathrm{R}}$, of 29 Japanese inland earthquakes with a magnitude range from $M_{\mathrm{w}}=5.6$ to 7.0 . The method is based on the work of Gutenberg and Richter in which the time integral of $S$-wave ground-motion velocitysquared is measured as a basic metric of the radiated energy. Only stations within a distance of $100 \mathrm{~km}$ are used to minimize complex path and attenuation effects. Unlike the teleseismic method that uses mainly $P$ waves, the use of $S$ waves which carry more than 95 per cent of the radiated energy allows us to obtain robust results. We calibrate the method using synthetic seismograms to modernize and improve the Gutenberg-Richter method. We compute synthetic seismograms for a source model of each event with a given source function (i.e. known $E_{\mathrm{R}}$ ), the actual mechanism and the source-station geometry. Then, we compare the given $E_{\mathrm{R}}$ with the computed energy metric to correct for the unknown effect of wave propagation and the mechanism. The use of downhole records minimizes the uncertainty resulting from the site response. Our results suggest that the currently available estimates of $E_{\mathrm{R}}$ from teleseismic data are probably within a factor of 3 , on average, of the absolute value. The scaled energy $e_{\mathrm{R}}($ $=E_{\mathrm{R}} / M_{0}$ ) is nearly constant at about $3 \times 10^{-5}$ over a magnitude range from $M_{\mathrm{w}}=5.6$ to 7.0 with a slight increasing trend with $M_{\mathrm{w}}$. We found no significant difference in $e_{\mathrm{R}}$ between dip-slip and strike-slip events.
\end{abstract}

Key words: Downhole methods; Body waves; Earthquake dynamics; Earthquake hazards; Earthquake source observations; Site effects.

\section{INTRODUCTION}

Radiated energy, $E_{\mathrm{R}}$, in earthquakes is a fundamental physical quantity in seismology. It is important for understanding the basic physics of seismic rupture, evolution of fault zones, and generation of strong ground motions. Comparison of the radiated energy with the strain energy involved in faulting is key to a better understanding of rupture physics (e.g. Husseini \& Randall 1976; Husseini 1977; Kikuchi \& Fukao 1988; Kikuchi 1992; Venkataraman \& Kanamori 2004; Kanamori \& Rivera 2006). Although the total strain (or potential) energy involved in seismic rupture is still hard to estimate, with some assumptions we can estimate a portion of the strain energy relevant to seismic rupture, which is generally termed as the available strain energy (Husseini 1977). The ratio of $E_{\mathrm{R}}$ to the total strain energy, $\eta$, and the ratio of $E_{\mathrm{R}}$ to the available strain energy, $\eta_{R}$, are called the seismic efficiency and the radiation efficiency, respectively, and are the key parameters for understanding the physics of earthquakes.

Although the accuracy of the radiated energy estimation has improved significantly (e.g. Boatwright \& Choy 1986; Pérez-Campos et al. 2003; Convers \& Newman 2011; Denolle \& Shearer 2016;
Ye et al. 2016a), a few issues remain regarding currently used energy estimation methods. Most of the recent studies use teleseismic body waves. In this method, it is difficult to remove the effect of surface reflections such as $\mathrm{pP}$ and $\mathrm{sP}$ for large complex shallow earthquakes. For deep earthquakes, this may not be an issue. Also, $S$ waves that carry most of the energy are attenuated during propagation. As a result, in most studies, only $P$ waves are used, but $P$ waves carry only less than 5 per cent of the radiated energy, and the total energy estimated from $P$ waves can be subject to large uncertainties. Another difficulty is that the $P$ waves used for energy estimation can be strongly perturbed by a 3-D near-source structure, attenuation and scattering during propagation which are often difficult to account for accurately. This is especially problematic for strike-slip earthquakes for which teleseismic signals are nodal.

In contrast, the energy estimation method using regional data can use $S$ waves which carry most of the radiated energy. However, the propagation path effects and complex receiver site response are often difficult to account for accurately. The classic works by Gutenberg \& Richter $(1942,1956)$ used this method, but they were aware of the significant effects of site response (Gutenberg \& Richter 
$1955,1956)$. The time-domain integration method of Gutenberg \& Richter (1956) is most straightforward and robust and has been used by many investigators since then (e.g. Seidl \& Berckhemer 1982; Bolt 1986; Kanamori et al. 1993; Dineva \& Mereu 2009). However, the time-domain method generally provides only radiated energy. If other source parameters such as seismic moment, stress drop and source spectrum are desired, frequency-domain integration methods must be used. Most recent studies use the frequency-domain method (e.g. Boatwright \& Fletcher 1984; Singh \& Ordaz 1994; Abercrombie 1995; Ide et al. 2003; Prieto et al. 2004; Nishitsuji \& Mori 2013; Ko \& Kuo 2016; Plata-Martinez et al. 2019). This method often uses empirical Green's functions to correct for the complex path effects (e.g. Izutani \& Kanamori 2001; Venkataraman et al. 2002; Izutani 2005, 2008). Another method uses scattered wavefields measured from coda waves to determine the source spectrum (e.g. Mayeda \& Walter 1996; Mayeda et al. 2005; Baltay et al. 2011; Malagnini et al. 2014). A distinct advantage of this method is that the source spectrum can be estimated with only a few, even one, stations; however a parametric model for the spectra is generally required due to finite bandwidth issues arising from the imperfectness of the empirical Green's function.

The most suitable method depends on many factors such as the magnitude of the events, and available instruments. For events with $5.5 \leq M_{\mathrm{w}} \leq 7$, most methods work satisfactorily, and use of downhole instruments, if available, can significantly reduce the uncertainties. For small events with $M_{\mathrm{w}}<5.5$, the correction for attenuation and site response becomes critically important, and use of downhole instruments are desirable. For events with $M_{\mathrm{w}}<3$, accurate measurements are extremely difficult without downhole instruments. For large events with $M_{\mathrm{w}}>7$, the regional method is often difficult to use because of the large source dimension and possible strong directivity.

Singh \& Ordaz (1994) found notable differences in the energy estimates from teleseismic data and local data. Pérez-Campos et al. (2003) showed that most of these differences can be eliminated with accurate corrections for attenuation and site effects in both teleseismic and regional methods. For events with $5.5 \leq M_{\mathrm{w}} \leq$ 7 regional and teleseismic estimates of the energy by different investigators seem to agree within a factor of 3 in most cases, regardless of the method used (e.g. time- or frequency-domain method.).

Gutenberg \& Richter's (1956) method is the simplest and in principle can be most robust, because it captures all the energy without filtering before the energy is substantially attenuated. However, many factors such as the radiation pattern and the complex near-surface effects are not explicitly accounted for. Here we combine the old yet robust Gutenberg \& Richter's (1956) method with modern downhole records to reduce the uncertainties caused by site effects. We account for the radiation pattern and path effects using synthetic seismograms computed for all the source-station combinations.

\section{GUTENBERG AND RICHTER'S METHOD}

Gutenberg and Richter attempted to estimate the radiated energy from regional ground- motion data as early as 1942 (Gutenberg \& Richter 1942, eq. 24 on p. 178). After several revisions, they finally obtained the following expression (Gutenberg \& Richter 1956, eq. 17 , p. 133) for energy (E) estimation for a point source.

$E=3 \pi^{3} h^{2} v t_{0} \rho\left(A_{0} / T_{0}\right)^{2}$.
In this expression, $A_{0}, T_{0}$ and $t_{0}$ are, respectively, the groundmotion displacement amplitude, period and the effective duration of the wave train. These parameters are not explicitly defined, but if the ground-motion velocity is harmonic, $V(t)=2 \pi\left(\frac{A_{0}}{T_{0}}\right) \cos \left(2 \pi t / T_{0}\right)$, then $\int_{0}^{t_{0}} V^{2}(t) \mathrm{d} t=2 \pi^{2}\left(\frac{A_{0}}{T_{0}}\right)^{2} t_{0}$ if $t_{0}$ is sufficiently longer than $T_{0}$. Thus, $2 \pi^{2} t_{0}\left(A_{0} / T_{0}\right)^{2}$ can be generally written as $\int_{0}^{t_{0}} V^{2}(t) \mathrm{d} t$. In (1), $v$ and $\rho$ are the wave speed and the density in the crust near the station, respectively. Here we consider $S$ waves and denote them by $\beta$ and $\rho$. Then,

$\rho \beta \int_{0}^{t_{0}} V^{2}(t) \mathrm{d} t$

is the energy flux per unit area taken normal to the ray path. In (1) $h$ is the straight distance from the hypocentre to the station, and we denote it by $r$. Substituting these in (1), we can write GutenbergRichter's formula as

$E=\frac{1.5}{4}\left[4 \pi r^{2} \rho \beta \int_{0}^{t_{0}} V^{2}(t) \mathrm{d} t\right]$.

This expression can be interpreted as follows. In a homogeneous whole space, the total energy carried by $\mathrm{S}$ wave, $E_{\beta}$, can be obtained by multiplying the energy flux (2) by $4 \pi r^{2}$, that is

$E_{\beta}=4 \pi r^{2} \rho \beta \int_{0}^{t_{0}} V^{2}(t) \mathrm{d} t$.

Gutenberg \& Richter (1956) divided (4) by 4 to account for the free surface amplification, multiplied (4) by 1.5 to account for the energy carried by $P$ wave and derived (3). In practice, Gutenberg \& Richter (1956) computed (1) at many stations and took the average to estimate the radiated energy.

\section{APPLICATION OF THE GUTENBERG-RICHTER'S METHOD TO MODERN DATA}

Although Gutenberg and Richter made several assumptions and simplifications in deriving (3), it is instructive to apply their method to modern data and advance it to obtain more accurate estimates of radiated energy. Since the energy carried by $P$ waves is less than 5 per cent of that by $S$ waves for a double couple source, rather than 50 per cent as Gutenberg \& Richter (1956) assumed, we drop the factor 1.5 in (3) and use the following for energy estimation.

$E_{\beta}=\pi r^{2} \rho \beta \int_{0}^{t_{0}} V^{2}(t) \mathrm{d} t$.

Hereafter, we ignore the contribution from $P$ waves, and assume $E_{R} \approx E_{\beta}$.

As shown above, this expression is for a very simple model in a homogeneous whole space; the radiation pattern, path effects and site response are all ignored. Nevertheless, since it is an expression approximating the radiated energy, we will use it as an energy metric in the following.

As an example, we apply this method to the 2016 Tottori, Japan, earthquake $\left(M_{\mathrm{w}}=6.2\right)$ because Ross et al. (2018) made a detailed analysis of the rupture process and estimated $E_{R}$ to be $5.7 \times 10^{13} \mathrm{~J}$. In Ross et al. (2018), accurate determination of the moment-rate function was an important objective. They determined the momentrate function by deconvolution of the observed waveforms using an empirical Green's function (EGF). The energy spectrum can be computed from the moment-rate function. However, deconvolution 
is well-known to be an unstable process. To stabilize deconvolution, Ross et al. (2018) had to low-pass filter the record at $f_{l}$. Also, to minimize the effect of noise at high frequency, they had to terminate the integration of the energy spectrum at a cut-off frequency $f_{c}$. After trial-and-error by varying $f_{l}$ and $f_{c}$ from 0.75 to $1.25 \mathrm{~Hz}$, Ross et al. (2018) obtained $E_{\mathrm{R}}=5.7 \times 10^{13} \mathrm{~J}$ after correcting for the missing energy caused by the cut-off of integration at $f_{c}$. Some uncertainties are inevitable due to the filtering, cut-off of integration, and correction for the missing energy. In this paper, we do not attempt to estimate the moment-rate function; we only estimate the integrated energy and we do not need to perform deconvolution, nor do we apply any filter at high frequency. Thus, all the energy is included in the wave train used for energy estimation.

Table 1 lists the relevant source parameters for the 2016 Tottori earthquake (Event \#26). For this event, many downhole seismograms from the Japanese KiK-net stations operated by the National Research Institute for Earth Science and Disaster Resilience (NIED) are available. Using these downhole data, we can minimize the effect of station site response which we believe is the major cause of uncertainty in energy estimates. Some advantages of using downhole stations have been demonstrated by, for example, Abercrombie (1995) and Venkataraman et al. (2006).

Fig. 1 shows $E_{R}$ measured for each station using (5). We use an $S$-wave time window from $2 \mathrm{~s}$ before the $S$-wave arrival time to $3 t_{c}$ after that where $t_{c}$ is the centroid time of the moment-rate function measured from the origin time. In the standard practice used by the Global Centroid Moment Tensor (GCMT) Project and the National Earthquake Information Center (NEIC), $t_{c}$ is the centroid time minus the origin time. Duputel et al. (2013) showed that $t_{c}$ is one of the most robust source parameters that can be determined from global data. The regression analysis between the seismic moment $M_{0}$ and $t_{c}$ gives the relationship $t_{c}=2.6 \times 10^{-6} M_{0}^{1 / 3}\left(M_{0}\right.$ in Nm, and $t_{\mathrm{c}}$ in $\mathrm{s})$. We estimate $t_{c}$ using this relationship from the seismic moment $M_{0}$.

We compute the theoretical $S$-wave arrival times using the crustal velocity model determined by Shibutani \& Katao (2005) for the Tottori region (Table 2). The ground-motion velocity is computed from the three component records by $V(t)=\left[V_{E}^{2}(t)+V_{N}^{2}(t)+V_{Z}^{2}(t)\right]^{1 / 2}$. Following Gutenberg \& Richter (1956) we use $\rho=2700 \mathrm{~kg} \mathrm{~m}^{-3}$, and $\beta=3400 \mathrm{~m} \mathrm{~s}^{-1}$. To minimize the effect of propagation path, we limit the distance to $100 \mathrm{~km}$. In this case most of the energy is carried by direct rays. The results are shown by black dots in Fig. 1 as a function of distance $(\Delta)$ and azimuth $\left(\varphi_{s}\right)$. Fig. 1 shows that the distance and azimuth dependence is small, and the scatter around the average is due to radiation pattern, path effect, and site response. The median of $E_{R}$ from all the stations is $E_{R}=4.3 \times 10^{13} \mathrm{~J}$ which agrees well with $E_{R}=5.7 \times 10^{13} \mathrm{~J}$ estimated by Ross et al. (2018) using a detailed rupture model. It is encouraging that Gutenberg \& Richter's simple method yields a reasonable estimate. Although the first-order geometrical distance correction is included in eq. (5), a close inspection of the data for all the events indicates a small distance dependence that can be approximated by exp $(k \Delta)$, with $\Delta$ in $\mathrm{km}$ and $k$ given by $-0.060734+0.007651 M_{\mathrm{w}}$. We determine the numerical constants by performing regression globally over all the events (Appendix). We assume that this distance dependence is due to anelastic attenuation. The small dependence on $M_{\mathrm{w}}$ reflects the decrease of the average frequency of $S$ waves with increasing $M_{\mathrm{w}}$. After correcting for the distance, we obtain $E_{R}=9.9 \times 10^{13} \mathrm{~J}$ for the energy metric for the 2016 Tottori earthquake.

\section{ESTIMATION OF $E_{R}$ FOR JAPANESE INLAND EARTHQUAKES}

The result for the Tottori earthquake is encouraging. It could be possible to develop a more detailed numerical method by including the effect of radiation pattern, path effects and site response, but it is difficult to accurately correct for the complex wave propagation effects in the real crust. Thus, in this paper we choose to implement a calibration method using synthetic seismograms to be described in the next section.

We apply the method to 29 inland earthquakes in Japan recorded with KiK-net. These events are shown in Fig. 2(a) and listed in Table 1 with the hypocentral and mechanism parameters. Fig. 2(b) shows all the KiK-net stations with the depth of downhole stations colour-coded.

Although the method is essentially the same as that used for the Tottori earthquake, for the purpose of introducing our calibration method, we reformulate it in a spherical coordinate $\operatorname{system}(r, \theta, \phi)$ with the origin at the hypocentre. Analogous to (5), we first estimate the total radiated energy, $E_{R}$, with (5) computed at a station by

$E_{R_{-} S t}=\left[\pi r^{2} \rho_{0} \beta_{0} \int_{0}^{t_{0}} v(t, r, \theta, \phi)^{2} \mathrm{~d} t\right]$,

where $r$ is the straight hypocentral distance, $r=\left(\Delta^{2}+H^{2}\right)^{1 / 2}$ ( $\Delta$ is epicentral distance, $H$ is depth), $\rho_{0}$ and $\beta_{0}$ are a representative density and $S$-wave speed near the surface, and $v(t, r, \theta, \phi)$ is the ground-motion velocity at the station. Here, we use $\rho_{0}=2700 \mathrm{~kg} \mathrm{~m}^{-3}$ and $\beta_{0}=3400 \mathrm{~m} \mathrm{~s}^{-1}$. Since $v(t, r, \theta, \phi)$ depends on the station location, $E_{R_{s} t}$ also varies with station. The results are shown in Fig. 3 for the 29 events we studied. Also shown in Fig. 3 are the results after the small distance dependence has been corrected by dividing $E_{R s t}$ by $\exp (k \Delta)$.

Hereafter, we denote the median of the station estimates $E_{R_{s t}}$ by $E_{R \text { saw }}$, and the median of $E_{R_{-} S t} / \exp (k \Delta)$ by $E_{R_{-} G R}$, and list them in Table 1.

\section{CALIBRATION}

As shown in the previous section, $E_{R_{-} G R}$ estimated from the energy metric (6) after distance correction is a good approximation, but the radiation pattern, propagation effects, and details of the free surface effects have not been accounted for. Thus, we write the final estimate of the radiated energy, $E_{R_{-} \text {final }}$, by

$E_{R_{-} \text {final }}=C_{R} E_{R_{-} G R}$,

where $C_{R}$ is a correction factor that includes the effects of radiation pattern, propagation effect, and other factors that are not accounted for in $E_{R_{-} G R}$.

To determine $C_{R}$, we use synthetic seismograms. We compute synthetic seismograms for all the KiKnet stations used for the events listed in Table 1 (about 3000 seismograms). We use the $\omega-k$ method and the basic software described in Herrman (2013) and Shibutani \& Katao's (2005) crustal structure. For the source moment-rate function we use an isosceles triangle with a half duration $t_{c}$ estimated from the seismic moment $M_{0}$ using the scaling relation $t_{c}=2.6 \times 10^{-6} M_{0}^{1 / 3}\left(t_{c}\right.$ in s, $M_{0}$ in Nm, Duputel et al. 2013). We denote the radiated energy metric thus computed for the synthetic seismograms by $E_{R_{-} G R_{-} s y n}$. In this computation, we do not apply the distance correction because Shibutani \& Katao's (2005) crustal structure does not include anelastic attenuation. (Although the structure given in Table 2 has nominal values for $Q_{P}^{-1}$ and $Q_{S}^{-1}$ for numerical computation, their effects are insignificant.) 


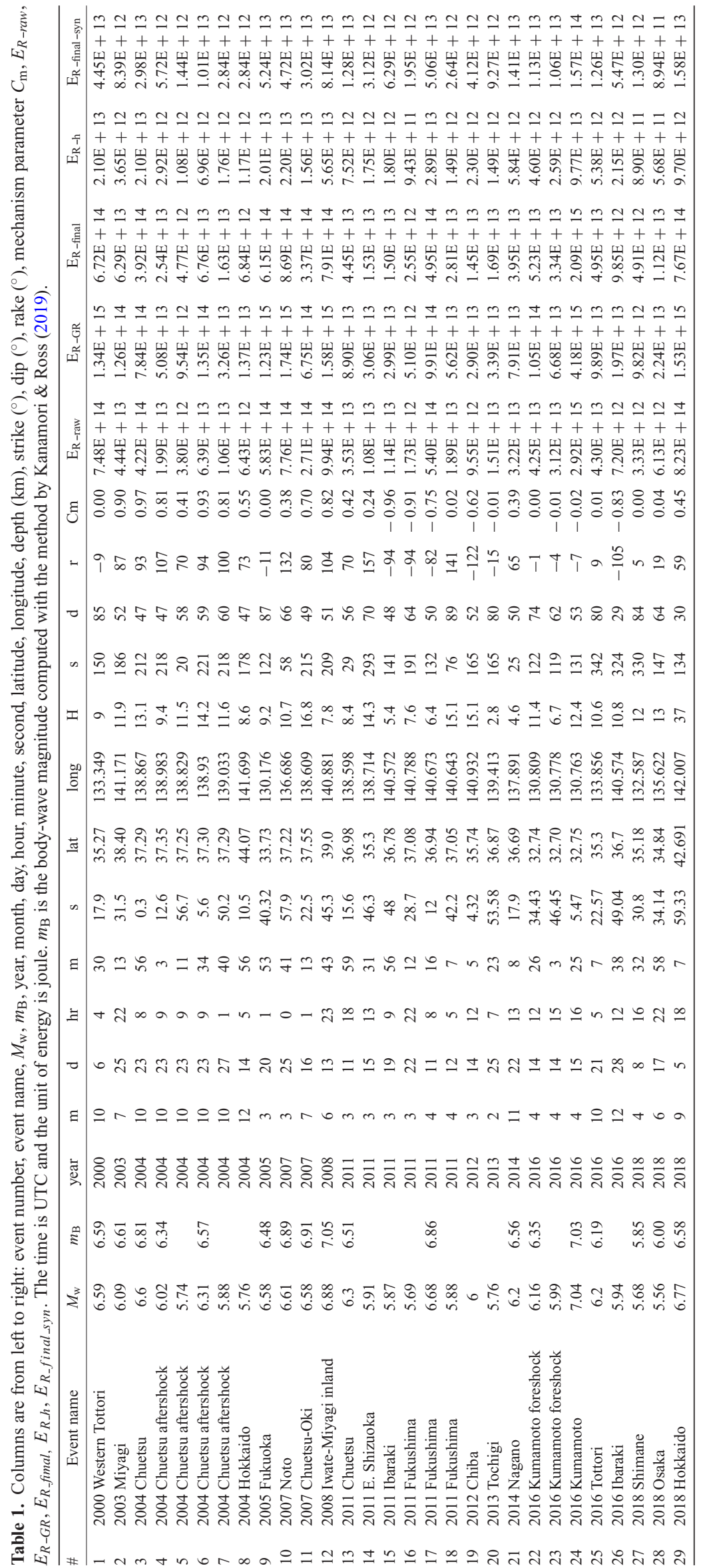



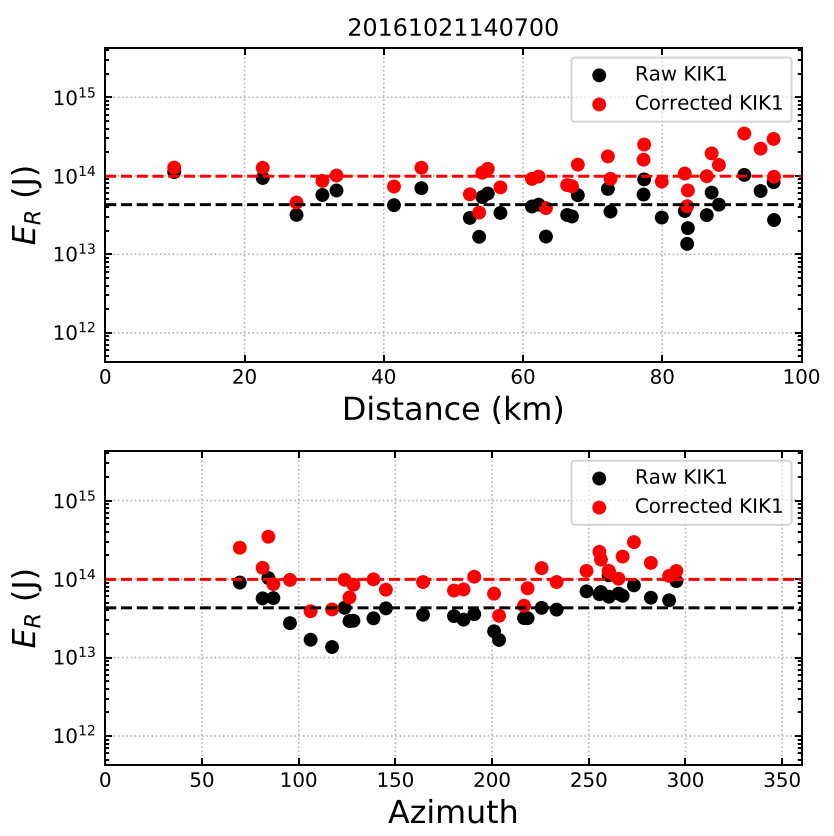

Figure 1. The energy metric given by eq. (5) for the 2016, $M_{\mathrm{w}}=6.2$, Tottori earthquake as a function of distance (top panel) and azimuth (bottom panel). Black dots are the uncorrected data, and red dots are the values after small distance correction has been applied. The black and red dashed lines indicate the median.

Table 2. Crustal model used.

\begin{tabular}{lccccc}
\hline \multicolumn{5}{c}{ (Modified from Shibutani \& Katao 2005) } \\
$\begin{array}{l}V_{P} \\
H(\mathrm{~km})\end{array}$ & $\begin{array}{c}V_{S} \\
\left(\mathrm{~km} \mathrm{~s}^{-1}\right)\end{array}$ & $\left(\mathrm{km} \mathrm{s}^{-1}\right)$ & $\rho\left(\mathrm{g} \mathrm{cm}^{3}\right)$ & $Q_{P}$ & $Q_{S}$ \\
\hline 1.0 & 4.71 & 2.55 & 2.786 & 1000 & 500 \\
2.0 & 5.70 & 3.24 & 2.786 & 1000 & 500 \\
2.0 & 5.96 & 3.50 & 2.786 & 1000 & 500 \\
2.0 & 6.15 & 3.61 & 2.786 & 1000 & 500 \\
3.0 & 6.23 & 3.64 & 2.786 & 1000 & 500 \\
3.0 & 6.24 & 3.64 & 2.786 & 1000 & 500 \\
3.0 & 6.24 & 3.66 & 2.786 & 1000 & 500 \\
14.0 & 6.60 & 3.81 & 2.786 & 1600 & 500 \\
\hline
\end{tabular}

Since the synthetic seismograms are computed for a given moment-rate function and mechanism, we can estimate the radiated energy at the hypocentre. For a point moment tensor source in a homogeneous whole space, the far-field ground-motion velocity $v(t, r, \theta, \phi)$ at $(r, \theta, \phi)$ is given by,

$v(t, r, \theta, \phi)=\frac{\ddot{M}_{0}(t) R(\theta, \phi)}{4 \pi r \rho \beta^{3}}$,

where $\dot{M}_{0}(t)$ is the source moment-rate function, and $R(\theta, \phi)$ is the radiation pattern. Then, if the source duration is short enough not to significantly perturb the energy radiation from the source by reflected energy mainly from the free surface, the energy radiated through a small sphere surrounding the hypocentre is given by

$E_{R \_h}=\rho_{h} \beta_{h} \int_{S} \mathrm{~d} S \int_{0}^{t_{0}} v^{2}(t, r, \theta, \phi) \mathrm{d} t=\frac{\overline{R^{2}}}{4 \pi \rho_{h} \beta_{h}^{5}} \int_{0}^{\infty} \ddot{M}_{0}^{2}(t) \mathrm{d} t$,

where $\overline{R^{2}}=\frac{1}{4 \pi r^{2}} \int_{S} R(\theta, \phi)^{2} \mathrm{~d} S$, and $\rho_{h}$ and $\beta_{h}$ are the density and $S$-wave speed at the source, respectively. For a double couple $\overline{R^{2}}=\frac{2}{5}$ (e.g. Brune 1970). Then, for our triangular moment-rate function, the total energy radiated by $S$ wave is given by

$$
\begin{aligned}
E_{R\lrcorner h} & =\left(\frac{1}{10 \pi \rho_{h} \beta_{h}^{5}}\right) \int_{0}^{\infty} \ddot{M}_{0}^{2}(t) \mathrm{d} t=\left(\frac{1}{10 \pi \rho_{h} \beta_{h}^{5}}\right) \frac{2 M_{0}^{2}}{t_{c}^{3}} \\
& =\left(\frac{1}{10 \pi \rho_{h} \beta_{h}^{5}}\right) \frac{2 M_{0}}{\left(2.6 \times 10^{-6}\right)^{3}}
\end{aligned}
$$

(in SI units). We compute $E_{R_{-} h}$ for all the events using $M_{0}, \rho_{h}$ and $\beta_{h}$. Then, comparing $E_{R_{-} G R_{-} s y n}$ and $E_{R_{-} h}$, we determine $C_{R}$ in eq. (7). In general $C_{R}$ can be different for each station, and each event because it depends on the mechanism and the sourcestation geometry. However, a log-log plot of $E_{R_{-} G R_{-} s y n}$ versus $E_{R_{-} h}$ computed for all the 29 events (Fig. 4) indicates that the ratio $E_{R\lrcorner h} / E_{R_{-} G R_{-} s y n}$ is approximately constant at 0.5 regardless of the events. Thus, this result justifies a use of single value 0.5 for $C_{R}$ for the entire data set.

In the above we assumed that the source duration is short enough not to affect the energy radiation from the source. If this condition is not satisfied eq. (9) cannot be used. Rivera \& Kanamori (2014) showed that the effect can be significant for events with large slip at shallow depths. Deep earthquakes and strike-slip earthquakes are essentially unaffected by the free surface, but shallow dipping reverse-fault or normal-fault events can be affected. Since none of the events we studied is low-angle dip-slip, we assumed that the effect is relatively small. Also, Denolle (2019) showed that earthquakes radiate energy most efficiently in the first 10-30 per cent of the overall rupture duration. Thus, we consider that the effect of free surface is not significant for the events we studied. However, since this is still an unresolved question, eq. (9) should be carefully used for large shallow low-angle dip slip events.

\section{RESULTS}

Using the correction factor $C_{R}$ thus determined we estimate the radiated energy, $E_{R_{-} \text {final }}=C_{R} E_{R_{-} G R}$ and list them in Table 1 together with all the relevant data for the earthquakes studied.

\subsection{Comparison with the results from other regional studies}

For 7 events out of the 29 events in Table $1, E_{\mathrm{R}}$ has been estimated using the EGF method by several investigators. Table 3 compares the results. Out of 13 cases, 9 of them agree within a factor of 3 .

\subsection{Absolute value of $E_{\mathrm{R}}$}

As mentioned earlier, teleseismic estimation of $E_{\mathrm{R}}$ involves many assumptions, and it is difficult to estimate the uncertainty in the absolute values (e.g. Ye et al. 2018). In contrast, because of the use of $S$ waves and our calibration method using synthetic seismograms, we believe that our regional method provides a more precise estimate of the absolute value of $E_{\mathrm{R}}$. Here we compare our results with the teleseismic estimates listed in two catalogues, one is IRIS EQenergy (IRIS DMC 2013) and the other, the USGS catalogue (ftp://ha zards.cr.usgs.gov/NEICPDE/olderPDEdata/manuscript/ also Choy, written communication, 2019). Fig. 5(a) shows the comparison. The EQenergy catalogue has $E_{\mathrm{R}}$ for 17 events out of the 29 events we studied. For these 17 events, 15 and 10 events are within a factor of 3 and 2, respectively, of our estimates. The USGS catalogue has $E_{\mathrm{R}}$ for 11 events out of the 29 events we studied. For these 11 events, 9 and 5 events are within a factor of 3 and 2, respectively, of our 
(a)

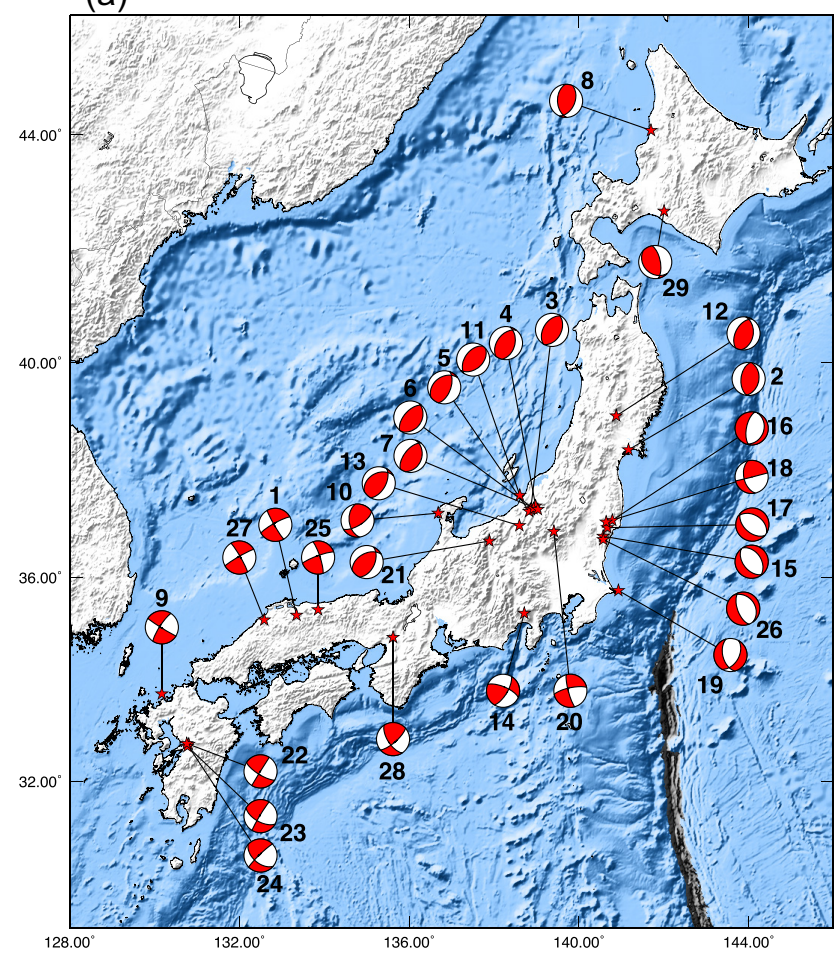

(b)

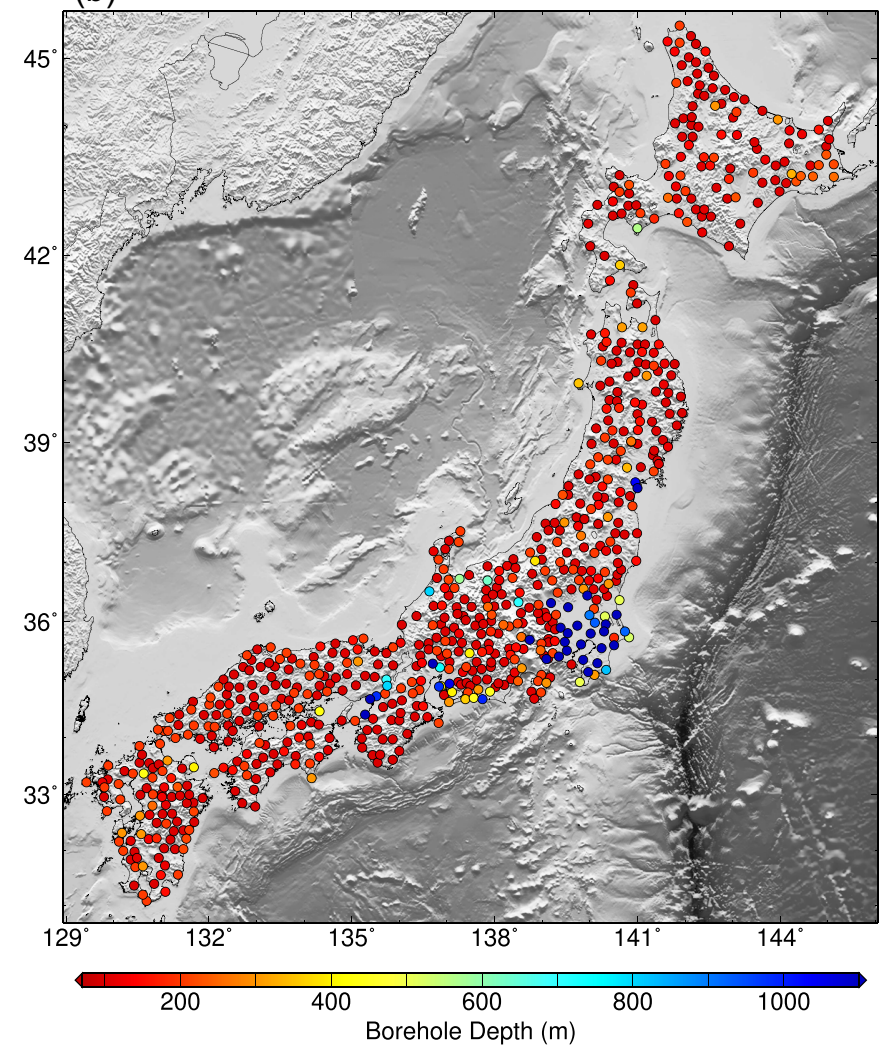

Figure 2 (a) Twenty-nine Japanese inland earthquakes studied in this paper. The number attached to the mechanism diagram corresponds to the event number listed in Table 1. (b) Depth of KiK-net downhole sensors.

estimates. These results are only for the Japanese inland events for an $M_{\mathrm{w}}$ range of 5.6-7.0, yet it is useful to know that teleseismic and regional estimates are by and large consistent within a factor of 3 .

For 9 events out of the 29 events, the radiated energy $E_{\mathrm{R}}$ is estimated with the method used by Ye et al. (2016a) for teleseismic events (L. Ye, written communication, 2019). Fig. 5(b) shows the comparison between these estimates and our regional values. Closed and open symbols are the values (teleseismic) integrated to 1 and $2 \mathrm{~Hz}$, respectively, and the red symbols indicate strike-slip events. The teleseismic and regional estimates agree within a factor of 3 in most cases.

\subsection{Dependence on the earthquake mechanism}

Choy \& Boatwright (1995), Choy \& McGarr (2002) and several other investigators found that the scaled energy $e_{\mathrm{R}}=E_{\mathrm{R}} / M_{0}$ or the apparent stress $\sigma_{a} \equiv \mu e_{R}$ ( $\mu$ is the rigidity) estimated from teleseismic data for strike-slip earthquakes is generally larger than that for dip-slip earthquakes. However, since teleseismic $P$ waves are nodal for strike slip earthquakes, the accuracy of the scaled energy for strike slip earthquakes has been debated (Newman \& Okal 1998). Since the nodal signals are strongly affected by scattered energy near the source, it is difficult to accurately estimate the radiated energy of strike-slip earthquakes from teleseismic $P$ waves.

The regional $S$-wave data include nearly 95 per cent of the radiated energy regardless of the source mechanism, and estimates from the regional data provide a more accurate comparison of the scaled energy for strike-slip and dip-slip earthquakes.
Fig. 6 shows $e_{\mathrm{R}}$ for the events we studied (from Table 1) plotted as a function of the mechanism parameter $C_{m}$ (Shearer et al. 2006) which is a useful scalar parameter that depends mainly on the rake. We do not see any obvious dependence of $e_{\mathrm{R}}$ on $C_{m}$ at least for the group of earthquakes we studied.

\subsection{Scaled energy $e_{\mathrm{R}}$}

Fig. 7 shows the scaled energy $e_{\mathrm{R}}$ for the 29 events as a function of $M_{\mathrm{w}}$. Since the magnitude range of our data set is small (5.7-7.0), it is hard to determine a trend, but $e_{\mathrm{R}}$ is approximately constant at $3 \times 10^{-5}$ with a slight increasing trend with $M_{\mathrm{w}}$. Comparing these values with $e_{\mathrm{R}}$ for smaller $\left(M_{\mathrm{w}} \sim 3\right)$ events from Abercrombie (1995, downhole measurements), Venkataraman et al. (2006, downhole), Izutani \& Kanamori (2001) and Izutani $(2005,2008)$ and Malagnini et al. (2014) suggests that $e_{\mathrm{R}}$ may increase by an order of magnitude from events with $M_{\mathrm{w}}=3$ to 7 . However, other investigators (e.g. Prieto et al. 2004; Baltay et al. 2011, 2014) found comparable $e_{\mathrm{R}}$ for small and large events.

\section{ESTIMATION OF $E_{R}$ USING SURFACE RECORDS}

Although our main objective is to use downhole records to avoid possible complexity caused by near-surface structures, we also measure $E_{\mathrm{R}}$ using surface records of KiK-net and K-NET (NIED) stations to investigate the effect of the near-surface structures on energy estimations. More details on site response and free-surface effects are given in the sections S-4 and S-5 in the Supporting Information. 

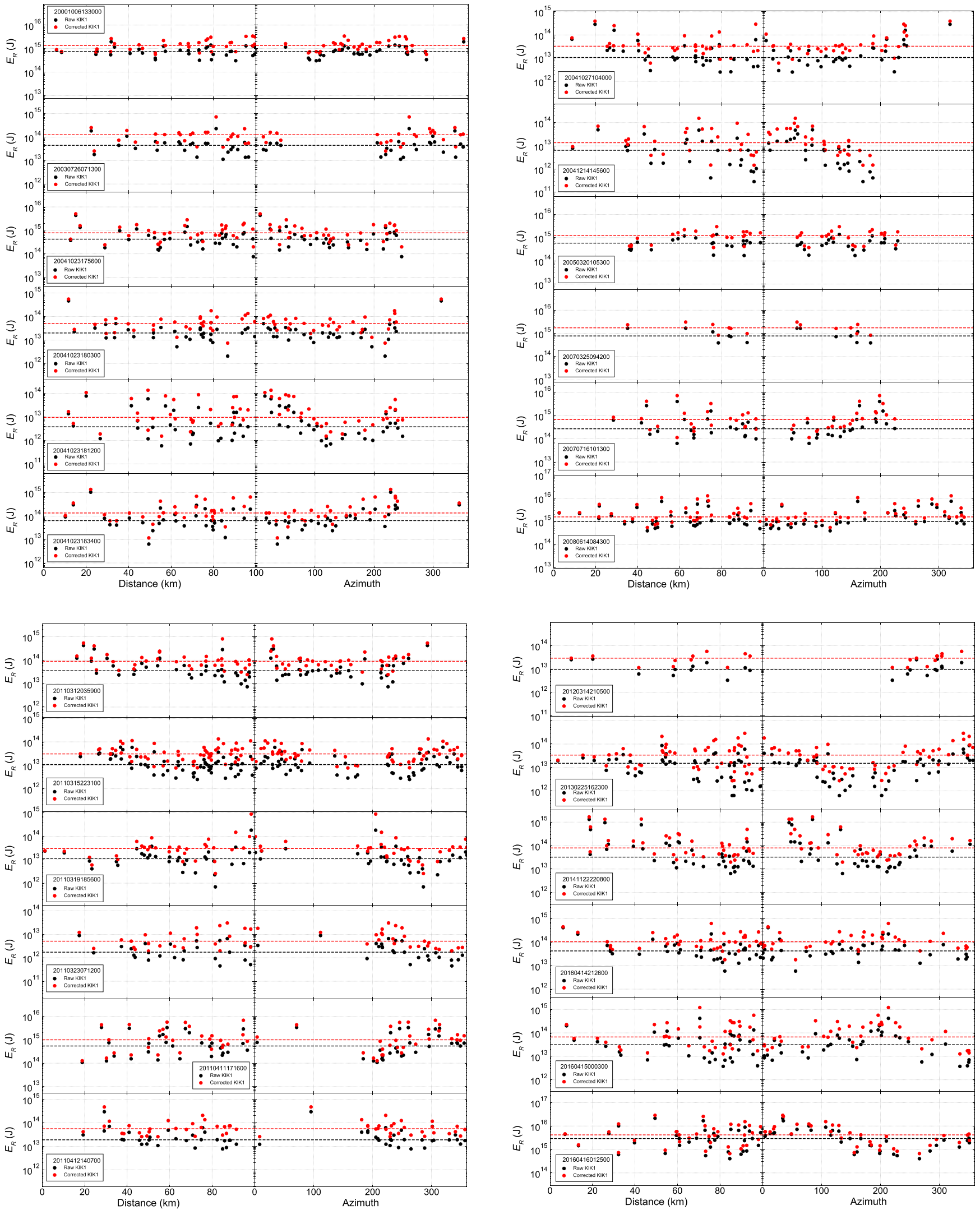

Figure 3. $E_{R_{s t}}$ (black dots) and $E_{R_{-} s t} / \exp (k \Delta)$ (red dots) for the 29 earthquakes listed in Table 1 as a function of distance (left-hand panel) and azimuth (right-hand panel). The black and red dashed lines indicate the medians. 


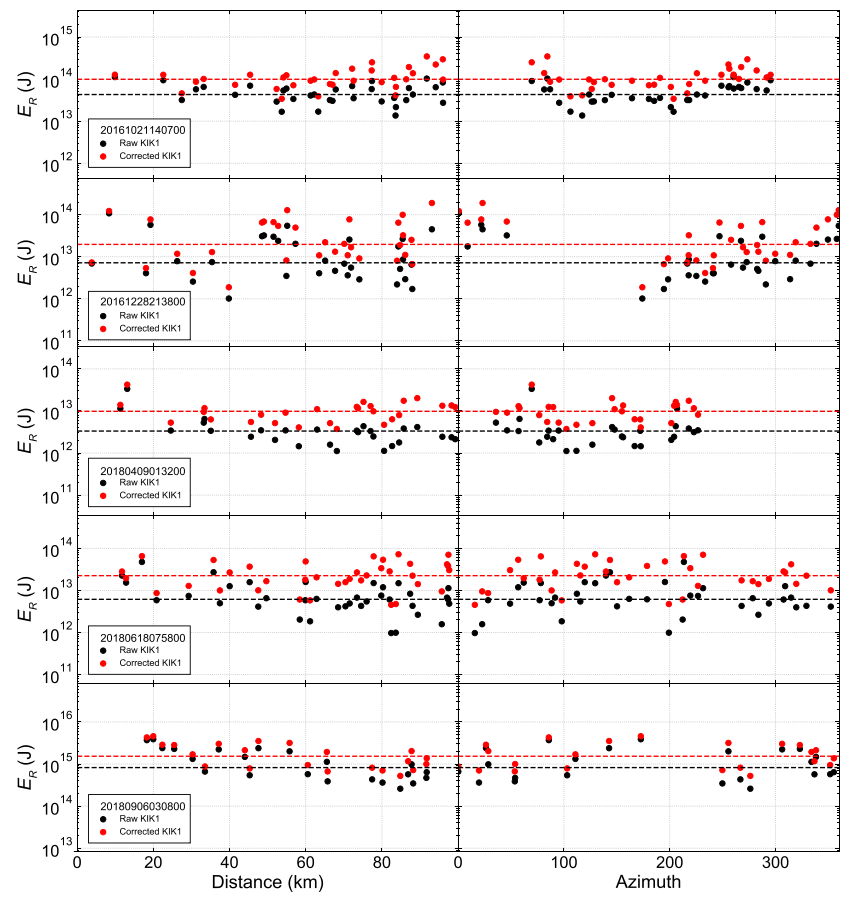

Figure 3. continued.

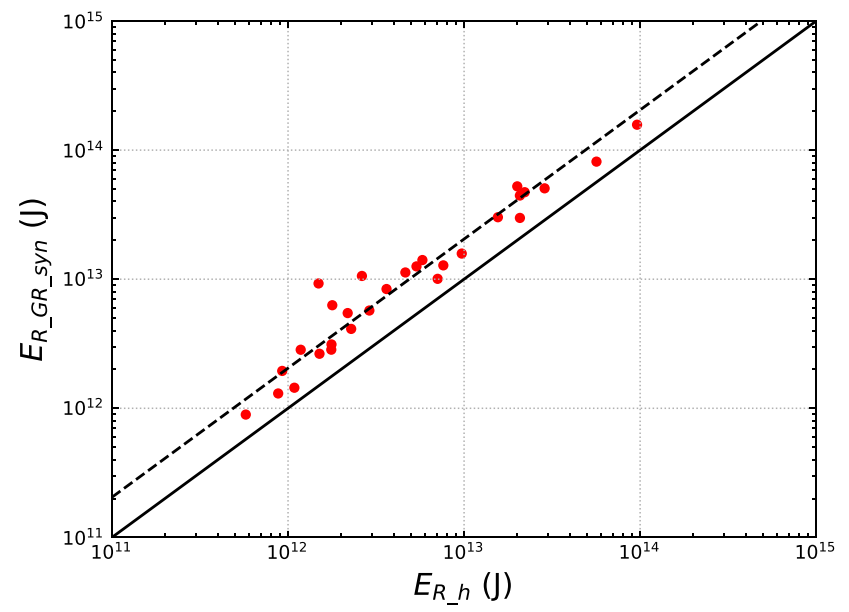

Figure 4. The relation between $E_{R_{-} G R_{s} s y}$ and the radiated energy computed at the source, $E_{R_{-} h}$, from the synthetic seismograms. The ratio $C_{R}=E_{R_{-} h} / E_{R_{-} G R_{-} s y n}$ gives the correction factor.

The results for all 29 earthquakes are shown in Fig. S1 (KiK-net) and Fig. S2 (K-NET) in the Supporting Information for this paper. In general, the station-to-station scatter of the $E_{\mathrm{R}}$ values is much larger than that for the case with downhole stations. The median values of $E_{\mathrm{R}}$ are 2-10 times larger than those for the downhole case as shown in Fig. 8.

Fig. 9 shows the ratio of $E_{\mathrm{R}}$ from the surface record to $E_{\mathrm{R}}$ from the downhole record of KiK-net stations for the 2018 Osaka-Kyoto event $\left(M_{\mathrm{w}}=5.6\right)$. Hereafter we call this ratio $v^{2}$ amplification factor. Many stations for this event are on a soft structure. Out of 37 stations, the $v^{2}$ amplification factor is larger than 10 at 11 stations. Fig. 9 compares the waveforms at station FKIH04 where the $v^{2}$ amplification is very large, about 100, and the effect of site amplification is evident. In this case, it would be difficult to correct for the site response to accurately estimate $E_{\mathrm{R}}$. However, at some stations like HYGH14, the site response is not very large, and it could be corrected either empirically or numerically. Fig. 9 also shows a similar comparison for the 2016 Tottori earthquake $\left(M_{\mathrm{w}}=6.2\right)$. The $v^{2}$ amplification factor is larger than 5 at 6 stations out of 34 stations. The $v^{2}$ amplification factors for all the 29 events are shown in Fig. S3 in the Supporting Informtion.

Comparison of Fig. 3 and Fig. S1 clearly demonstrates the advantage of using downhole stations for accurate determinations of $E_{\mathrm{R}}$. However, dense downhole stations are not available everywhere, and surface stations may have to be used in many cases. It would be difficult to correct for site response accurately for stations with a very large amplification factor, but for the stations with a moderate amplification factor, site response could be corrected adequately either empirically or numerically.

\section{DISCUSSION}

\subsection{Directivity}

Directivity can have a significant impact on energy estimation (e.g. Ma \& Archuleta 2006), especially for very large strike slip earthquakes, like the 1992 Landers earthquake. However, it is not easy to estimate its effect as it depends on how coherent the rupture propagation is. For example, if the rupture speed is uniform at the $S$-wave speed, the radiated waveform in the rupture direction becomes pulse-like with large energy flux, leading to strong directivity. However, if the actual rupture propagation is not uniform, the azimuthal dependence (aside from the radiation pattern) may not be very large. In our data set, the 2016 Kumamoto earthquake may have the largest dirctivity effect because it is a strike slip event with approximately unilateral rupture propagation towards NE. In this case, the peaks of the $S$-wave radiation pattern and directivity coincide and a large azimuthal variation is expected. To see this effect, Fig. 10(a) compares the observed and synthetic $E_{\mathrm{R}_{-} \mathrm{GR}}$ for this event. Since the synthetic case is for a point source, there is no directivity effect, and we can see only the azimuthal radiation pattern. In contrast, the azimuthal pattern of the observed $E_{\mathrm{R}}$ clearly shows the directivity effect.

Fig. 10(b) shows a similar plot for the 2016 Tottori earthquake $\left(M_{\mathrm{w}}=6.2\right)$. Although there are no stations in the exact rupture direction (NNW), the azimuthal pattern is generally consistent with the radiation pattern. Fig. 10(c) shows a similar plot for the 2000 Tottori earthquake $\left(M_{\mathrm{w}}=6.6\right)$. Again the pattern is consistent with the radiation pattern. This event is more bilateral than unilateral (Ohmi et al. 2002), and directivity effect is not very large. Thus, for the events in our data set, the directivity effect is significant only for the largest strike slip Kumamoto earthquake. We note, however, that the rupture propagation may not be as simple as one can imagine from a simple unilateral rupture like the Haskell model (Haskell 1964). For both the 2000 and 2016 Tottori earthquakes, Fukuyama et al. (2003) and Ross et al. (2018), respectively, found evidence for off-fault seismicity structure which indicates that the rupture geometry is more complicated than the simple unilateral or bilateral geometry. In this study, we minimize the effect of directivity on $E_{\mathrm{R}}$ estimates by taking the median of the energies measured from all the stations from the wide azimuthal range, rather than making corrections using a simple rupture geometry. As Fig. 10(a) shows, this practice is reasonable for the 2016 Kumamoto event. However, for unilateral strike slip events larger than $M_{\mathrm{w}}=7$, or when the azimuthal coverage is limited, directivity can bias the energy estimates. 
Table 3. Estimates of radiated energy (in $10^{14} \mathrm{~J}$ ) (ER, (1), (2), (3), (4), (5), (6)).

\begin{tabular}{lcllllllll}
\hline Event & Year & $M_{\mathrm{W}}$ & $\mathrm{E}_{\mathrm{R}}$ & $(1)$ & $(2)$ & $(3)$ & $(4)$ & $(5)$ & (6) \\
\hline Tottori & 2000 & 6.59 & 6.7 & 3.0 & & & & 1.4 & \\
Chuetsu & 2004 & 6.6 & 3.9 & & 3.2 & & 2.9 & 6.3 & \\
Fukuoka & 2005 & 6.58 & 6.2 & & & & & 1.6 & \\
Noto & 2007 & 6.61 & 8.7 & & & 6.8 & & 1.2 & \\
Chuetsu-Oki & 2007 & 6.58 & 3.3 & & & & 19 & 5.9 & \\
Iwate-Miyagi & 2008 & 6.88 & 7.9 & & & & 18 & 6.2 & \\
Tottori & 2016 & 6.2 & 0.50 & & & & & & 0.57 \\
\hline
\end{tabular}

\section{Note:}

$E_{R}$ : This study

(1): Izutani \& Kanamori (2001) EGF;

(2): Izutani (2005) EGF;

(3): Izutani (2008) EGF;

(4): Baltay et al. (2011) EGF coda;

(5): Malagnini et al. (2014) EGF coda;

(6): Ross et al. (2018) EGF MRF.

(a)

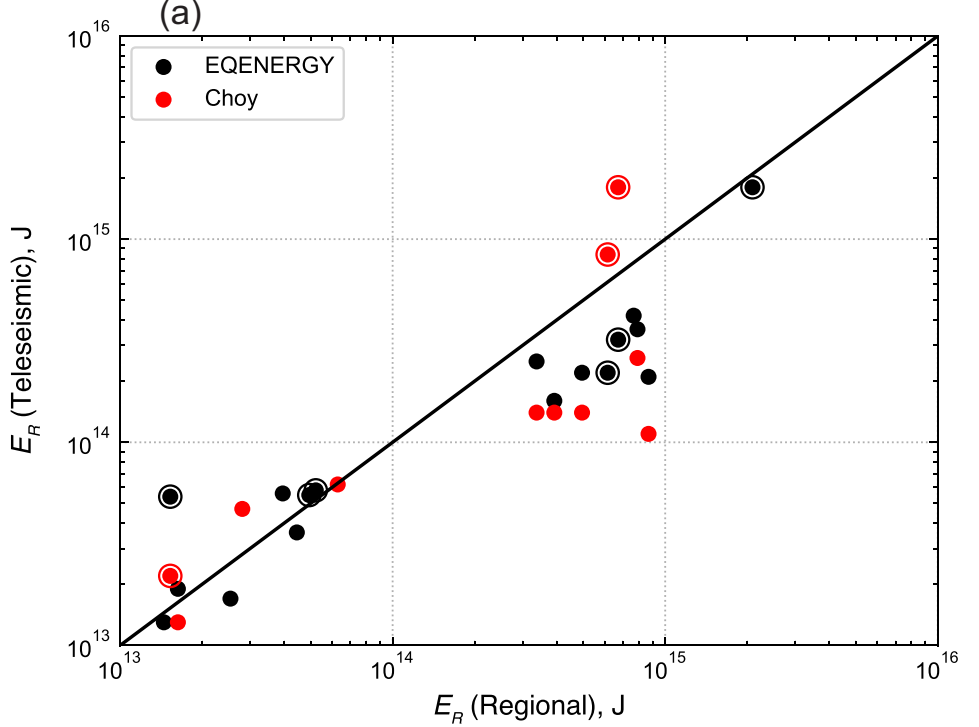

(b)

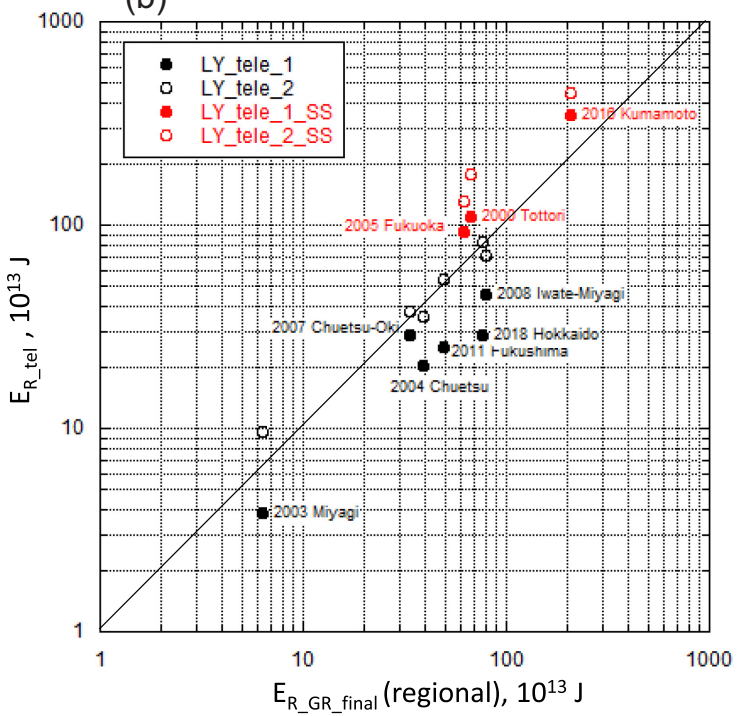

Figure 5 (a) Comparison of $E_{\mathrm{R}}$ measured from teleseismic data and regional data, $E_{\mathrm{R} \text { final. }}$ Two teleseismic data sets are used. Black: from IRIS EQenergy (Convers \& Newman 2011; IRIS DMC 2013); Red: USGS (Choy, written communication, 2019). The encircled symbols indicate strike-slip earthquakes. (b) Comparison between the regional estimates of $E_{\mathrm{R}}$ (this study) with $E_{\mathrm{R}}$ estimated with the method used by Ye et al. (2016a) (L. Ye, written communication, 2019). Closed and open symbols are the values (teleseismic) integrated to 1 and $2 \mathrm{~Hz}$, respectively, and the red symbols indicate strike-slip events.

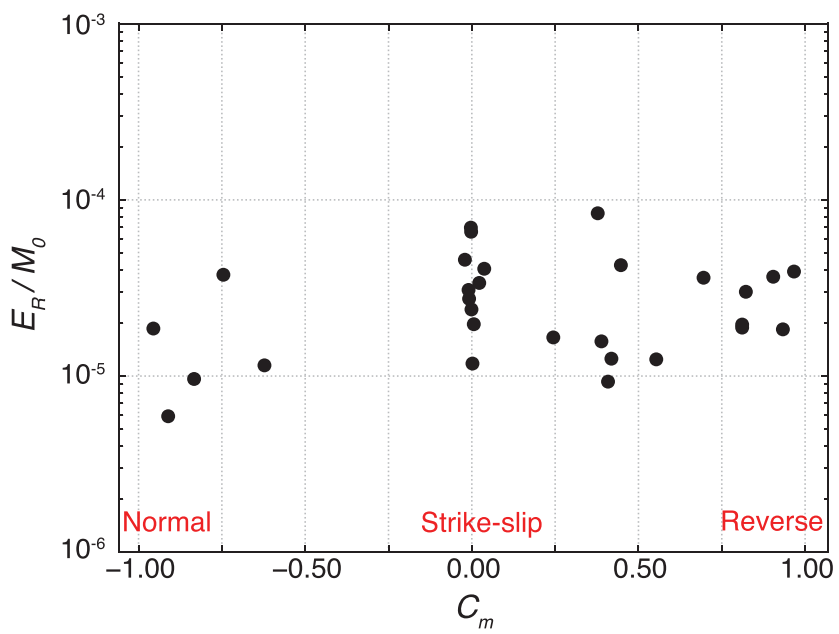

Figure 6. The scaled energy $e_{R}=E_{R} / M_{0}$ as a function of the mechanism parameter $C_{m}$. $C_{m}$ ranges from -1.0 for normal fault to 1.0 for reverse fault.

\subsection{Scaled energy}

As we found in Fig. 5, the $E_{\mathrm{R}}$ estimates we obtained from the regional data agree reasonably well with teleseismic estimates, within a factor of 2-3 in most cases. This good agreement gives us confidence in the $E_{\mathrm{R}}$ estimates currently available either from regional or teleseismic data. The scaled energy $e_{R}=E_{R} / M_{0}$ for the 29 large $\left(M_{\mathrm{w}}=5.6-7.0\right)$ Japanese onshore events ranges from $5 \times 10^{-6}$ to $8 \times 10^{-5}$, but is relatively constant overall. Many determinations of $e_{\mathrm{R}}$ have been made by various investigators. For comparison, Table 4 lists some examples for large events with $M_{\mathrm{w}} \geq 7$. Only approximate values and ranges are listed.

In a simple stress relaxation model of earthquakes where the stress on the fault drops from the initial stress $\sigma_{0}$ to the residual stress $\sigma_{1}$, with stress drop $\Delta \sigma$ and the average stress $\bar{\sigma}=\left(\sigma_{0}+\sigma_{1}\right) / 2$, the scaled energy is given by $e_{R}=\eta\left(\frac{\bar{\sigma}}{\mu}\right)$ ( $\eta$ : seismic efficiency, $\mu$ : rigidity, Wyss \& Brune 1968; Savage \& Wood 1971; Husseini 1977). This means that constant- $e_{R}$ implies that earthquakes that occur in a higher stress environment have a lower seismic efficiency, 


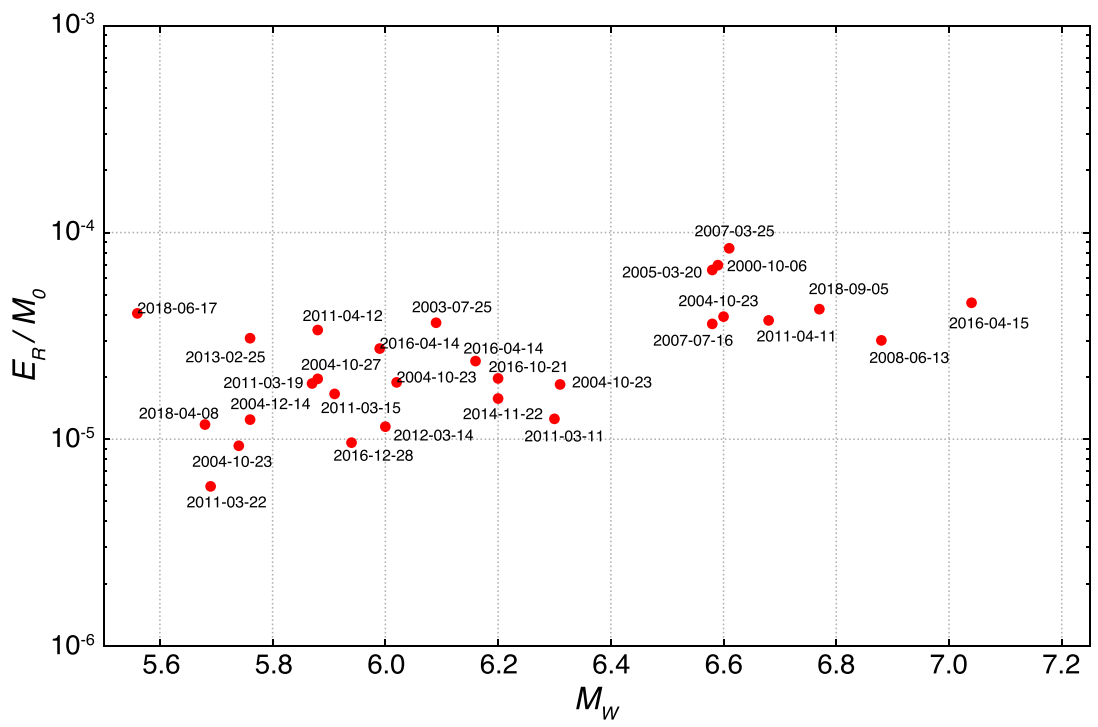

Figure 7. The scaled energy $e_{R}=E_{R} / M_{0}$ as a function of $M_{\mathrm{w}}$.

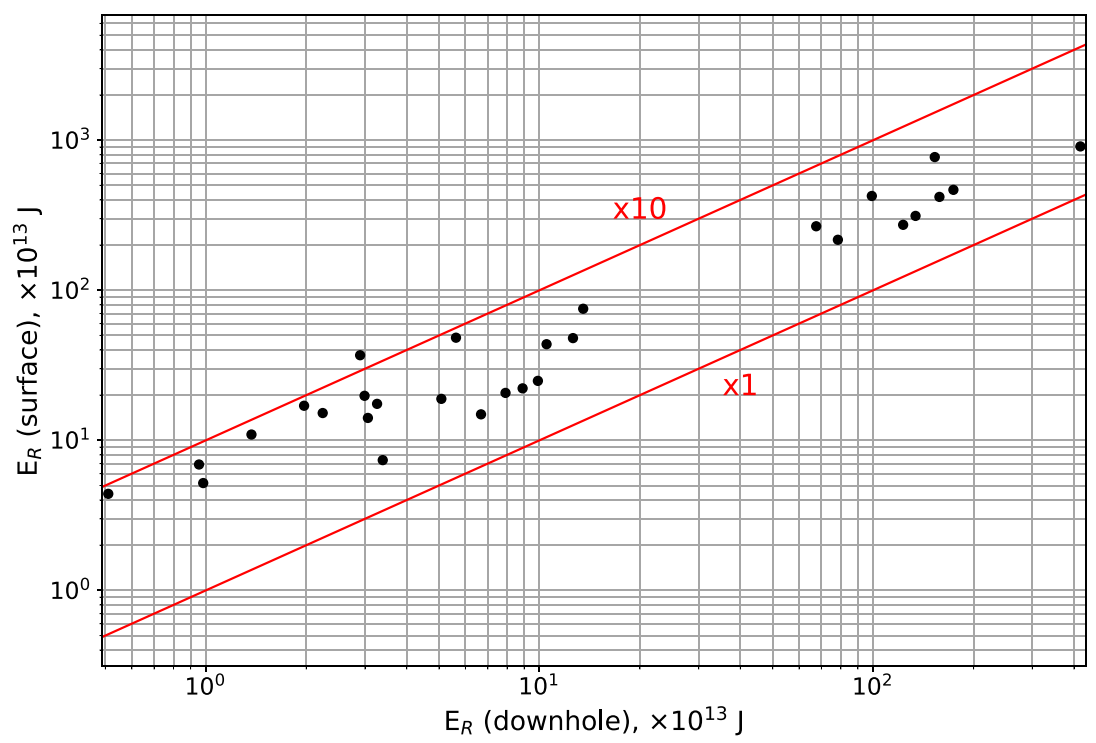

Figure 8. Comparison of the radiated energy $E_{R \text { raw }}$ measured at surface and downhole.

or larger energy dissipation. If the residual stress $\sigma_{1}$ is 0 , then $\bar{\sigma}=\Delta \sigma / 2$ and $e_{R}=\eta(\Delta \sigma / 2 \mu)$. If the residual stress is not 0 and is given by $\sigma_{1}=\xi \Delta \sigma(\xi$ is a constant $)$ then $\bar{\sigma}=(\Delta \sigma / 2)(1+2 \xi)$ and $e_{R}=\eta_{R}(\Delta \sigma / 2 \mu)$ where $\eta_{R} \equiv \eta(1+2 \xi)$ is often called the radiation efficiency (Husseini 1977) which is the upper bound of the efficiency; $\eta_{R}$ is also used as a proxy for $\eta$ with some assumptions (e.g. Kanamori \& Rivera 2006). In this context, as discussed in Ross et al. (2018), the comparison between the 2016 Tottori earthquake and the 2004 Parkfield, California, earthquake is interesting. These 2 earthquakes have about the same $e_{\mathrm{R}}$ (see Ross et al. 2018). Ross et al. (2018) estimated $e_{\mathrm{R}}=2 \times 10^{-5}$, and $\Delta \sigma$ to be 18-27 MPa for the Tottori earthquake. In contrast, Kim \& Dreger (2008) estimated the average stress drop of the 2004 Parkfield earthquake to be $2.3 \mathrm{MPa}$. If the residual stress is much smaller than $\Delta \sigma$, then $\bar{\sigma} \approx \Delta \sigma / 2$, and we can estimate $\eta$ of the 2016 Tottori earthquake and the Parkfied earthquake to be about 0.06 and 0.6 , respectively. The very long estimated repeat time of 4000-8000 years for the nearby Shikano fault (Kaneda \& Okada 2002), and the absence of obvious surface faulting suggest that the Tottori earthquake occurred on a fault at immature evolutionary stage, and requires large amounts of energy to develop a well-defined fault zone, with less energy for radiation. In comparison, for the Parkfield earthquake on the mature welldeveloped San Andreas fault, most of the strain energy was radiated as seismic waves. If the residual stress is not small, what we can determine is $\eta_{R}$ instead of $\eta$, and the statement above should be taken only qualitatively. However, recent studies suggest that for some earthquakes like the 2011 Tohoku earthquake and the 2010 Maule, Chile, earthquake, the residual stress is believed to be small (Hasegawa et al. 2011; Hardebeck 2012), suggesting that $\eta_{R}$ is a good proxy for $\eta$. 

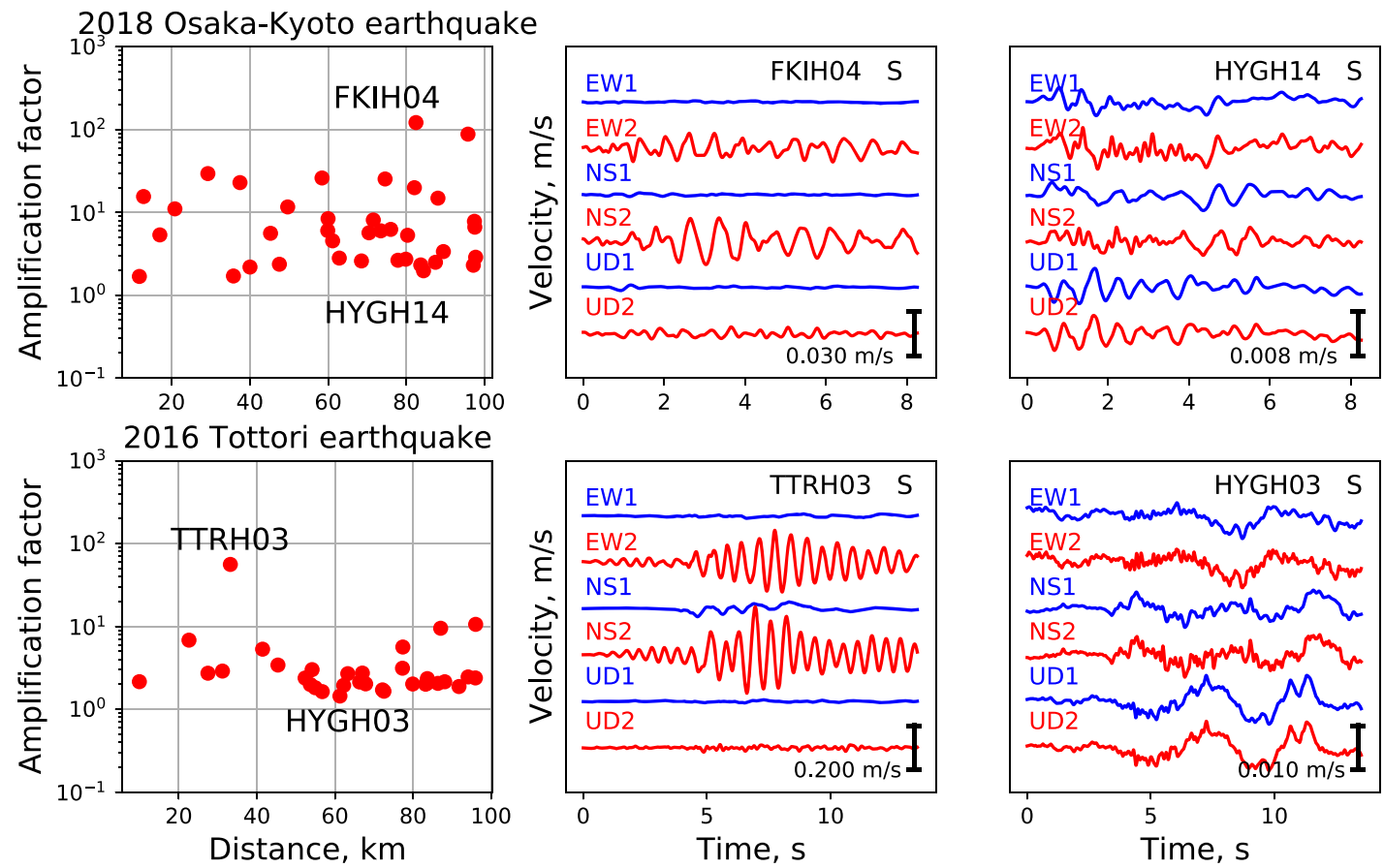

Figure 9. Examples of $v^{2}$ site amplification factor (leftmost figures). Top panel: 2018 Osaka-Kyoto earthquake $\left(M_{\mathrm{W}}=5.6\right)$. Bottom panel: 2016 Tottori earthquake $\left(M_{\mathrm{w}}=6.2\right)$. Comparison of the ground-motion velocity records of $S$ wave at 2 typical stations. (NS1, EW1, UD1) and (NS2, EW2, UD2) indicate the 3 component records at downhole and surface, respectively.

(a) 2016 Kumamoto $(\# 24, M w=7.0)$

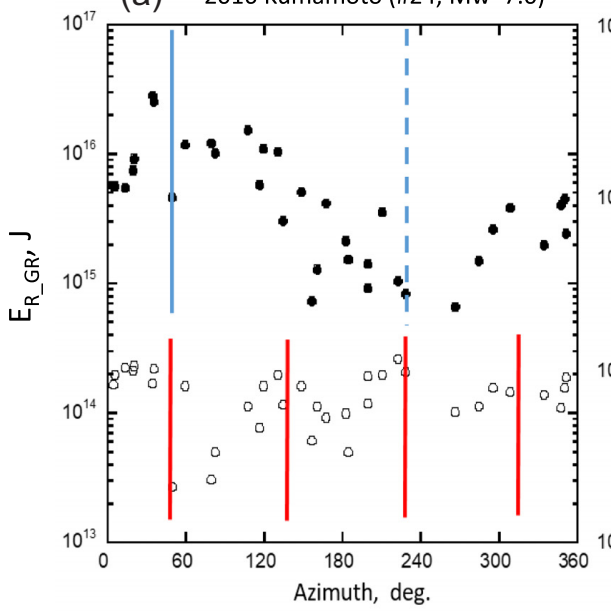

(b) 2016 Tottori $(\# 25, M w=6.2)$

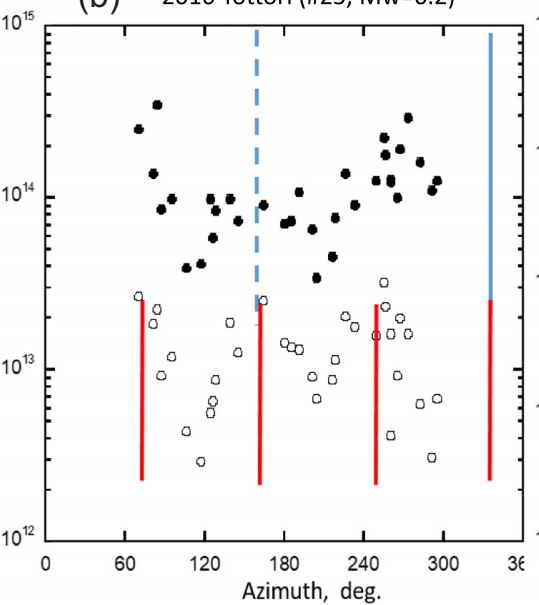

(c) 2000 Tottori $(\# 1, \mathrm{Mw}=6.6)$

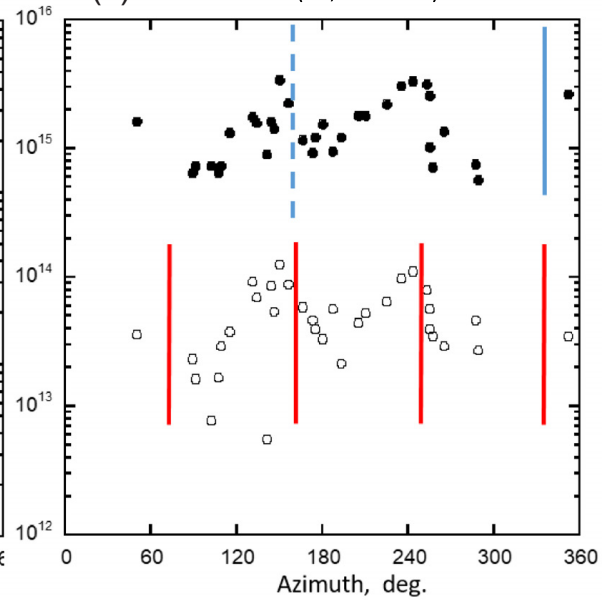

Figure 10. Azimuthal variation of the energy metric $E_{R_{-} s t}$ from the observed records (solid circle) and the synthetic records (open circles) for the 2016 Kumamoto earthquake, 2016 Tottori earthquake and 2000 Tottori earthquake. Blue solid and dashed lines indicate the azimuth of the maximum directivity and the minimum directivity, respectively. Red solid lines indicate the azimuth of the radiation pattern maximum. The difference in the absolute value of $E_{R_{-} G R}$ between the observed and synthetics is due to the difference in the shape of the moment-rate function between the observed and synthetic seismograms. This difference is not relevant to our analysis because the absolute value of $E_{R_{-} G R}$ of the synthetics is not used, and only the ratio of $E_{R_{-} G R}$ to $E_{R h}$ is used (eq. 7) for calibration.

Since we do not have well-constrained stress drop estimates for other earthquakes in our data set, we cannot make a detailed comparison, but the relatively constant $e_{\mathrm{R}}$ leads to an interesting general conclusion that an earthquake in a higher stress environment has a lower seismic efficiency.

If we look at the range of $e_{\mathrm{R}}$ variation for a group of events in different tectonic environments, we find that the range is fairly small as shown in Table 5 . Thus, the above conclusion may also apply to the events in each group, even deep earthquakes.

\subsection{Scale-independence}

In the context of the present paper 'Scale Independence' means that the scaled energy $e_{\mathrm{R}}$ (or apparent stress $\sigma_{\mathrm{a}}$ ) does not vary with $M_{\mathrm{w}}$. As shown by Ide \& Beroza (2001), the scaled energy $e_{\mathrm{R}}$ values reported by various investigators display a large variation (over 3 orders of magnitude ) with $M_{\mathrm{w}}$. Ide \& Beroza suggested that some of the variations are due to inadequate correction for path effects or limited pass-band of the measurements. Their suggestion 
Table 4. Example of scaled Energy $e_{\mathrm{R}}$ (for $M_{\mathrm{w}} \geq 7$ ).

\begin{tabular}{lccl}
\hline Group & \multicolumn{1}{c}{$e_{\mathrm{R}}($ range $)$} & $e_{\mathrm{R}}$ (average or median) & \multicolumn{1}{c}{ Reference } \\
\hline Global shallow & $9 \times 10^{-6}$ to $1 \times 10^{-4}$ & $1.2 \times 10^{-5}$ & Choy et al. $(2006)$ \\
Subduction-zone thrust & $1 \times 10^{-6}$ to $5 \times 10^{-5}$ & $8 \times 10^{-6}$ & Choy et al. $(2006)$ \\
Global Normal-fault & $2 \times 10^{-6}$ to $7 \times 10^{-5}$ & $1.210^{-5}$ & Choy et al. $(2006)$ \\
Global strike-slip & $1 \times 10^{-5}$ to $8 \times 10^{-4}$ & $7.5 \times 10^{-5}$ & Choy et al. (2006) \\
Global & $2 \times 10^{-6}$ to $2 \times 10^{-4}$ & & Denolle \& Shearer (2016) \\
Global & $10^{-6}$ to $10^{-4}$ & & Newman \& Okal (1998) \\
Great earthquakes & $1 \times 10^{-5}$ to $1 \times 10^{-4}$ & & Baltay et al. $(2014)$ \\
\hline
\end{tabular}

Table 5. Scaled energy $e_{\mathrm{R}}$ for events in different tectonic environments (for $M_{\mathrm{w}} \geq 7$ ).

\begin{tabular}{lccl}
\hline Group & \multicolumn{1}{c}{$e_{\mathrm{R}}$ (range) } & Average or median & \multicolumn{1}{c}{ Reference } \\
\hline Large Interplate & $4 \times 10^{-6}$ to $2 \times 10^{-5}$ & & Meng et al. $(2015)$ \\
Large Interplate & $4 \times 10^{-6}$ to $3 \times 10^{-5}$ & $1.06 \times 10^{-5}$ & Ye et al. $(2016 \mathrm{a})$ \\
Large Intraplate & $2 \times 10^{-5}$ to $5 \times 10^{-5}$ & & Meng et al. (2015) \\
Tsunami earthquakes & $8 \times 10^{-7}$ to $3 \times 10^{-6}$ & & Meng et al. $(2015)$ \\
Tsunami earthquakes & $1 \times 10^{-6}$ to $3 \times 10^{-6}$ & & Ye et al. $(2016 \mathrm{a})$ \\
Large deep earthquakes & $1.6 \times 10^{-5}$ to $5 \times 10^{-5}$ & & Ye et al. $(2016 \mathrm{~b})$ \\
& & Jia et al. (2019) \\
\hline
\end{tabular}

appears correct in general, but the details are not resolved yet. For large events, $e_{\mathrm{R}}$ values reported by various investigators are approximately constant within a group of a specific type of earthquakes (e.g. megathrust events, tsunami earthquakes, shallow crustal earthquakes, intraplate earthquakes, and deep earthquakes, see Table 5), but for events smaller than $M_{\mathrm{w}}=5.5$, or even smaller events with $M_{\mathrm{w}}<3.5$, reported $e_{\mathrm{R}}$ values are highly variable. Whether this large variation is real or due to measurement error is not yet resolved. The results obtained from downhole records (e,g. Abercrombie 1995; Venkataraman et al. 2006) and those with the EGF method are probably more reliable; $e_{\mathrm{R}}$ values for events with $M_{\mathrm{w}} \sim$ 3 from these results tends to be smaller. The results obtained from coda waves (Mayeda \& Walter 1996; Mayeda et al. 2005; Malagnini et al. 2014) indicate a tendency for $e_{\mathrm{R}}$ to decrease toward smaller $M_{\mathrm{w}}$. If these results are combined with those for large events, $e_{\mathrm{R}}$ increases with $M_{\mathrm{w}}$ up to about $M_{\mathrm{w}}=5$, where self-similarity begins to hold. However, studies by Prieto et al. (2004) and Baltay et al. (2010) suggest self-similarity over a broader $M_{\mathrm{w}}$ range. Also, Oth et al. (2010) made an extensive analysis of KiK-net downhole data and found large variations (more than 2 orders of magnitude) of $e_{\mathrm{R}}$, but concluded that the variation of measured $e_{\mathrm{R}}$ is due to the scatter of stress drop. Their values of $e_{\mathrm{R}}$ for larger events are similar to ours. Since stress drop and $e_{\mathrm{R}}$ are not independent for the $\omega^{2}$-type models, their result means that despite the observed large variability of both $e_{\mathrm{R}}$ and stress drop, the average $e_{\mathrm{R}}$ shows no trend with $M_{\mathrm{w}}$. In contrast, a recent study by Trugman \& Shearer (2017) shows that the average stress drop increases by an order of magnitude for $M_{\mathrm{w}}=2-4$ for several regions in southern California.

\section{CONCLUSION}

Combination of downhole stations and calibration using synthetic seismograms allows us to use the fairly simple method originating from the classic Gutenberg \& Richter's study to obtain accurate estimates of the radiated energy $E_{\mathrm{R}}$ using regional $S$ waves. Since $S$ waves carry more than 95 per cent of the total radiated energy, the method is simpler and more robust than that using teleseismic data. The results from the 29 Japanese inland earthquakes with $M_{\mathrm{w}}=5.6-7.0$ suggest that the currently available estimates of $E_{\mathrm{R}}$ from teleseismic data are probably within a factor of 3 , on average, of the absolute value. The scaled energy $e_{\mathrm{R}}\left(=E_{\mathrm{R}} / M_{0}\right)$ is nearly constant at about $3 \times 10^{-5}$ over a magnitude range from $M_{\mathrm{w}}=5.8$ to 7.0, with a slight increasing trend with $M_{\mathrm{w}}$. We found no significant difference in $e_{\mathrm{R}}$ between dip-slip and strike-slip events we studied. However, our data base is relatively small, and more definitive conclusions must await further accumulation of data.

\section{ACKNOWLEDGEMENTS}

The KiK-net and K-NET data used in this study were provided by the National Research Institute for Earth Science and Disaster Resilience (NIED) of Japan. We thank Françoise Courboulex and an anonymous reviewer for their comments and suggestions, MenAndrin Meier for providing us with the results of Vs30 computed for the KiK-net downhole station, George Choy and Lingling Ye for providing us with the teleseismic energy estimates for some of the events we studied, and Sunyoung Park for discussion on nearsurface wave interactions.

\section{REFERENCES}

Abercrombie, R.E., 1995. Earthquake source scaling relationships from -1 to $5 \mathrm{M}_{\mathrm{L}}$ using seismograms recorded at 2.5-km depth, J. geophys. Res., 100(B12), 24 015-24036.

Baltay, A., Ide, S., Prieto, G. \& Beroza, G., 2011. Variability in earthquake stress drop and apparent stress, Geophys. Res. Lett., 38, L06303, doi:10.1029/2011GL046698.

Baltay, A.S., Beroza, G.C. \& Ide, S., 2014. Radiated energy of great earthquakes from teleseismic empirical Green's function deconvolution, Pure appl. Geophys., 171, 2841-2862.

Baltay, A., Prieto, G. \& Beroza, G.C., 2010. Radiated seismic energy from coda measurements and no scaling in apparent stress with seismic moment, J. geophys. Res., 115, B08314, doi:10.1029/2009JB006736.

Boatwright, J. \& Choy, G.L., 1986. Teleseismic estimates of the energy radiated by shallow earthquakes, J. geophys. Res., 91, 2095-2112.

Boatwright, J. \& Fletcher, J.B., 1984. The partition of radiated energy between $\mathrm{P}$ and $\mathrm{S}$ waves, Bull. seism. Soc. Am., 74, 361-376.

Bolt, B.A., 1986. Seismic energy release over a broad frequency band, Pure appl. Geophys., 124(4-5), 919-930.

Brune, J.N., 1970. Tectonic stress and the spectra of seismic shear waves from earthquakes, J. geophys. Res., 75, 4997-5009.

Choy, G.L. \& Boatwright, J.L., 1995. Global patterns of radiated seismic energy and apparent stress, J. geophys. Res., 100, 18 205-18 228. 
Choy, G.L. \& McGarr, A., 2002. Strike-slip earthquakes in the oceanic lithosphere: observations of exceptionally high apparent stress, Geophys. J. Int., 150, 506-523.

Choy, G.L., McGarr, A., Kirby, S.H. \& Boatwright, J., 2006. An overview of the global variability in radiated energy and apparent stress, in Earthquakes: Radiated Energy and the Physics of Faulting, pp. 43-57, eds Abercrombie, R. McGarr, A. Di Toro, G. \& Kanamori, H., American Geophysical Union.

Convers, J.A. \& Newman, A.V., 2011. Global evaluation of large earthquake energy from 1997 through mid-2010, J. geophys. Res., 116, B08304, doi: 10.1029/2010JB007928.

Denolle, M.A., 2019. Energetic onset of earthquakes, Geophys. Res. Lett., 46(5), 2458-2466.

Denolle, M.A. \& Shearer, P.M., 2016. New perspectives on self-similarity for shallow thrust earthquakes, J. geophys. Res., 121(9), 6533-6565.

Dineva, S. \& Mereu, R., 2009. Energy magnitude: a case study for southern Ontario/western Quebec (Canada), Seismol. Res. Lett., 80, 136-148.

Duputel, Z., Tsai, V.C., Rivera, L. \& Kanamori, H., 2013. Using centroid time-delays to characterize source durations and identify earthquakes with unique characteristics, Earth planet. Sci. Lett., 374, 92-100.

Fukuyama, E., Ellsworth, W.L., Waldhauser, F. \& Kubo, A., 2003. Detailed fault structure of the 2000 western Tottori, Japan, earthquake sequence, Bull. seism. Soc. Am., 93(4), 1468-1478.

Gutenberg, B. \& Richter, C.F., 1942. Earthquake magnitude, intensity, energy, and acceleration, Bull. seism. Soc. Am., 32, 163-191.

Gutenberg, B. \& Richter, C., 1955. Magnitude and energy of earthquakes, Nature, 176(4486), 795.

Gutenberg, B. \& Richter, C.F., 1956. Earthquake magnitude, intensity, energy, and acceleration: (Second paper), Bull. seism. Soc. Am., 46, 105-145.

Hardebeck, J.L., 2012. Coseismic and postseismic stress rotations due to great subduction zone earthquakes, Geophys. Res. Lett., 39, L21313, doi:10.1029/2012GL053438.

Hasegawa, A., Yoshida, K. \& Okada, T., 2011. Nearly complete stress drop in the $2011 \mathrm{M}_{\mathrm{W}} 9.0$ off the Pacific coast of Tohoku Earthquake, Earth, Planets Space, 63, 703-707.

Haskell, N.A., 1964. Total energy and energy spectral density of elastic wave radiation from propagating faults, Bull. seism. Soc. Am., 54(6A), $1811-1841$.

Herrmann, R.B., 2013. Computer programs in seismology: an evolving tool for instruction and research, Seism. Res. Lett., 84, 1081-1088.

Husseini, M.I., 1977. Energy balance for motion along a fault, Geophys. J. Int., 49, 699-714.

Husseini, M.I. \& Randall, M.J., 1976. Rupture velocity and radiation efficiency, Bull. seism. Soc. Am., 66(4), 1173-1187.

Ide, S. \& Beroza, G.C., 2001. Does apparent stress vary with earthquake size?, Geophys. Res. Lett., 28(17), 3349-3352.

Ide, S., Beroza, G.C., Prejean, S.G. \& Ellsworth, W.L., 2003. Apparent break in earthquake scaling due to path and site effects on deep borehole recordings, J. geophys. Res., 108(B5), 2271, doi:10.1029/2001JB001617.

IRIS DMC, 2013. Data Services Products: EQEnergy Earthquake energy \& rupture duration, https://doi.org/10.17611/DP/EQE.1.

Izutani, Y., 2005. Radiated energy from the mid Niigata, Japan, earthquake of October 23, 2004, and its aftershocks, Geophys. Res. Lett., 32, L21313, doi:10.1029/2005GL024116.

Izutani, Y., 2008. Radiated energy from the Noto Hanto, Japan, earthquake of March 25, 2007, and its aftershock, Earth, Planets Space, 60, 145-150.

Izutani, Y. \& Kanamori, H., 2001. Scale-dependence of seismic energy-tomoment ratio for strike-slip earthquakes in Japan, Geophys. Res. Lett., 28, 4007-4010.

Jia, Z., Shen, Z., Zhan, Z., Li, C., Peng, Z. \& Gurnis, M., 2019. The 2018 Fiji $\mathrm{M}_{\mathrm{w}} 8.2$ and 7.9 deep earthquakes: One doublet in two slabs, Earth planet. Sci. Lett., 115997.

Kanamori, H., Mori, J., Hauksson, E., Heaton, T.H., Hutton, L.K. \& Jones, L.M., 1993. Determination of earthquake energy release and ML using TERRAscope, Bull. seism. Soc. Am., 83, 330-333

Kanamori, H. \& Rivera, L., 2006. Energy partitioning during an earthquake, in Earthquakes: Radiated Energy and the Physics of Faulting, pp. 3-13, eds Abercrombie, R. McGarr, A. Di Toro, G. \& Kanamori, H., American Geophysical Union.

Kanamori, H. \& Ross, Z.E., 2019. Reviving $\mathrm{m}_{\mathrm{B}}$, Geophys. J. Int., 216(3), 1798-1816.

Kaneda, H. \& Okada, A., 2002. Surface rupture associated with the 1943 Tottori earthquake: compilation of previous reports and its tectonic geomorphological implications, Active Fault Res, 21, 73-91.

Kikuchi, M., 1992. Strain drop and apparent strain for large earthquakes, Tectonophysics, 211, 107-113.

Kikuchi, M. \& Fukao, Y., 1988. Seismic wave energy inferred from longperiod body wave inversion, Bull. seism. Soc. Am., 78, 1707-1724.

Kim, A. \& Dreger, D.S., 2008. Rupture process of the 2004 Parkfield earthquake from near-fault seismic waveform and geodetic records, J. geophys. Res., 113, B07308, doi:10.1029/2007JB005115.

Ko, J.Y.T. \& Kuo, B.Y., 2016. Low radiation efficiency of the intermediatedepth earthquakes in the Japan subduction zone, Geophys. Res. Lett., 43, 11 611-11619.

Ma, S. \& Archuleta, R.J., 2006. Radiated seismic energy based on dynamic rupture models of faulting, J. geophys. Res., 111(B5), B05315, doi:10.1029/2005JB004055.

Malagnini, L., Mayeda, K., Nielsen, S., Yoo, S.-H., Rawles, C. \& Boschi, E., 2014. Scaling transition in earthquake sources: a possible link between seismic and laboratory measurements, Pure appl. Geophys., 171, 26852707.

Mayeda, K. \& Walter, W.R., 1996. Moment, energy, stress drop, and source spectra of western United States earthquakes from regional coda envelopes, J. geophys. Res., 101, 11 195-11 208.

Mayeda, K., Gök, R., Walter, W.R. \& Hofstetter, A., 2005. Evidence for non-constant energy/moment scaling from coda-derived source spectra, Geophys. Res. Lett., 32, L10306, doi:10.1029/2005GL022405.

Meng, Q., Meeszel, D.S., Ye, L., Lay, T., Wiens, D.A., Jia, M. \& Cmmins, P.R., 2015. The 3 May $2006\left(\mathrm{M}_{\mathrm{w}}\right.$ 8.0) and 19 March $2009\left(\mathrm{M}_{\mathrm{w}}\right.$ 7.6) Tonga earthquakes: intraslab compressional faulting below the megathrust, $J$. geophys. Res., 120(9), 6297-6316.

Newman, A.V. \& Okal, E.A., 1998. Teleseismic estimates of radiated seismic energy: The $\mathrm{E} / \mathrm{M}_{0}$ discriminant for tsunami earthquakes, J. geophys. Res., 103, 26885-26898.

Nishitsuji, Y. \& Mori, J., 2013. Source parameters and radiation efficiency for intermediate-depth earthquakes in Northeast Japan, Geophys. J. Int., 196, 1247-1259.

Ohmi, S., Watanabe, K., Shibutani, T., Hirano, N. \& Nakao, S., 2002. The 2000 Western Tottori Earthquake, Earth, Planets Space, 54(8), 819-830.

Oth, A., Bindi, D., Parolai, S. \& Di Giacomo, D., 2010. Earthquake scaling characteristics and the scale-(in) dependence of seismic energy-tomoment ratio: insights from KiK-net data in Japan, Geophys. Res. Lett., 37, L19304, doi:10.1029/2010GL044572.

Pérez-Campos, X., Singh, S.K. \& Beroza, G.C., 2003. Reconciling teleseismic and regional estimates of seismic energy, Bull. seism. Soc. Am., 93, 2123-2130.

Plata-Martínez, R., Pérez-Campos, X. \& Singh, S.K., 2019. Spatial distribution of radiated seismic energy of three aftershocks sequences at Guerrero, Mexico, subduction zone, Bull. seism. Soc. Am., 109(6), 2556-2566.

Prieto, G.A., Shearer, P.M., Vernon, F.L. \& Kilb, D., 2004. Earthquake source scaling and self-similarity estimation from stacking $\mathrm{P}$ and $\mathrm{S}$ spectra, $J$. geophys. Res., 109, doi:10.1029/2004JB003084.

Rivera, L.A. \& Kanamori, H., 2014 . Estimation of radiated energy of recent great earthquakes using the normal-mode theory. In American Geophysical Union, Fall Meeting 2014, December 2014, Abstract ID S53B-4502.

Ross, Z.E., Kanamori, H., Hauksson, E. \& Aso, N., 2018. Dissipative intraplate faulting during the $2016 \mathrm{M}_{\mathrm{w}} 6.2$ Tottori, Japan earthquake, $J$. geophys. Res., 123, 1631-1642.

Savage, J.C. \& Wood, M.D., 1971. The relation between apparent stress and stress drop, Bull. seism. Soc. Am., 61(5), 1381-1388.

Seidl, D.u \& Berckhemer, H., 1982. Determination of source moment and radiated seismic energy from broadband recordings, Phys. Earth planet. Inter, 30, 209-213. 
Shearer, P.M., Prieto, G.A. \& Hauksson, E., 2006. Comprehensive analysis of earthquake source spectra in southern California, J. geophys. Res., 111, doi:10.1029/2005JB003979.

Shibutani, T. \& Katao, H., 2005. Group for the dense aftershock observations of the 2000 Western Tottori earthquake, high resolution 3-D velocity structure in the source region of the 2000 Western Tottori Earthquake in southwestern Honshu, Japan using very dense aftershock observations, Earth Planets Space, 57, 825-838.

Singh, S. \& Ordaz, M., 1994. Seismic energy release in Mexican subduction zone earthquakes, Bull. seism. Soc. Am., 84(5), 1533-1550.

Trugman, D.T. \& Shearer, P.M., 2017. Application of an improved spectral decomposition method to examine earthquake source scaling in southern California, J. geophys. Res., 122(4), 2890-2910.

Venkataraman, A. \& Kanamori, H., 2004. Observational constraints on the fracture energy of subduction zone earthquakes, J. geophys. Res., 109, doi:/10.1029/2003JB002349.

Venkataraman, A., Beroza, G.C., Ide, S., Imanishi, K., Ito, H. \& Iio, Y., 2006. Measurements of spectral similarity for microearthquakes in western Nagano, Japan, J. geophys. Res., 111, doi:10.1029/2005JB003834.

Venkataraman, A., Rivera, L. \& Kanamori, H., 2002. Radiated energy from the 16 October 1999 Hector Mine earthquake: regional and teleseismic estimates, Bull. seism. Soc. Am., 92, 1256-1265.

Wyss, M. \& Brune, J.N., 1968. Seismic moment, stress, and source dimensions for earthquakes in the California-Nevada region, J. geophys. Res., 73(14), 4681-4694.

Ye, L., Lay, T., Kanamori, H. \& Rivera, L., 2016a. Rupture characteristics of major and great $\left(\mathrm{M}_{\mathrm{w}} \geq 7.0\right)$ megathrust earthquakes from 1990 to 2015: 1. Source parameter scaling relationships, J. geophys. Res., 121, 826-844.

Ye, L., Lay, T., Kanamori, H., Zhan, Z. \& Duputel, Z., 2016b. Diverse rupture processes in the 2015 Peru deep earthquake doublet, $S c i$. Adv., 2, e1600581.

Ye, L., Kanamori, H. \& Lay, T., 2018. Global variations of large megathrust earthquake rupture characteristics, $S c i$. $A d v$, 4, eaao4915.

\section{SUPPORTING INFORMATION}

Supplementary data are available at $G J I$ online.

Figure S1. $E_{\mathrm{R}_{\text {raw }}}$ (black dots) and $E_{\mathrm{R} \_\mathrm{GR}}$ (green dots) for the 29 earthquakes listed in Table 1 as a function of distance (top panel) and azimuth (bottom panel) estimated from the KiK-net surface stations. The black and green dashed lines indicate the median.

Figure S2. $E_{\mathrm{R}_{\text {raw }}}$ (black dots) and $E_{\mathrm{R}_{\text {_GR }}}$ (blue dots) for the 29 earthquakes listed in Table 1 as a function of distance (top panel) and azimuth (bottom panel) estimated from the KiK-net surface stations. The black and blue dashed lines indicate the median.

Figure S3. The energy amplification factor $\left(E_{\mathrm{R}}\right.$ from the surface $\operatorname{record} / E_{\mathrm{R}}$ from the downhole record of KiK-net stations) for the
29 earthquakes listed in Table 1 . The results for every station are shown as a function of distance.

Figure S4. $v^{2}$ amplification factor as a function of $\mathrm{Vs} 30$.

Figure S5. $v^{2}$ amplification factor and the energy metric $E_{\mathrm{R}_{-} \mathrm{GR}}$ plotted as a function of azimuth. For plotting purposes $E_{\mathrm{R}_{-} \mathrm{GR}} / 1 \times 10^{10}$ are plotted.

Figure S6. Comparison of the surface and downhole velocity records at 3 frequency bands for station TTRH02.

Figure S7. Comparison of the surface and downhole velocity records at 3 frequency bands for station TTRH03.

Figure S8. Comparison of energy estimates obtained at stations with different depths. The event considered is the 2018 Osaka event $\left(M_{\mathrm{w}}=5.7\right)$.

Please note: Oxford University Press is not responsible for the content or functionality of any supporting materials supplied by the authors. Any queries (other than missing material) should be directed to the corresponding author for the paper.

\section{APPENDIX: MAGNITUDE-DEPENDENT DISTANCE CORRECTION}

Eq. (5) includes the geometrical spreading factor $1 / r$, but it does not account for the effect of anelastic attenuation. Since the distance range involved is $100 \mathrm{~km}$, the effect of attenuation is small, but small distance dependence is seen in our raw data. Thus, we apply the following simple magnitude-dependent distance correction by performing regression globally over all the events. Let $E_{i j}$ be the energy of the $j$ th event measured at station $i$. Then, we write

$\log E_{i j}=\log E_{j}^{0}+\left(\beta_{0}+\beta_{1} M_{j}\right) r_{i j}$,

where $M_{j}, r_{i j}, E_{j}^{0}$ are the magnitude of event $j(j=1,2, . . N)$, the distance between source $j$ and station $i\left(i=1,2,3, \ldots N_{S}\right)$, and the energy of event $j$ at the source, respectively. (Here, for simplicity, we assume that $N \mathrm{~s}$ is the same for all events.) Here, $E_{i j}$ are $N \times N_{S}$ observations (about 800) and $\beta_{0}, \beta_{1}$, $E_{1}^{0}, E_{2}^{0}, \ldots, E_{N}^{0}$ are $N+2$ unknown parameters to be determined. Denoting $\left(\log E_{1}^{0}, \log E_{2}^{0}, \log E_{3}^{0}, \ldots \ldots, \log E_{N}^{0}\right)$ by $\left(\beta_{2}, \beta_{3}, \beta_{4}, \ldots \ldots ., \beta_{N+1}\right)$, we can write eq. (A1) as

$\log E_{i j}=\beta_{0} r_{i j}+\beta_{1} r_{i j} M_{j}+\sum_{k=1}^{N} \beta_{k+1} \delta_{k j}$

we solve eq. (A2) for $\left(\beta_{0}, \beta_{1}, \beta_{2}, \beta_{3}, \beta_{4}, \ldots \ldots, \beta_{N+1}\right)$ using the least squares method. 